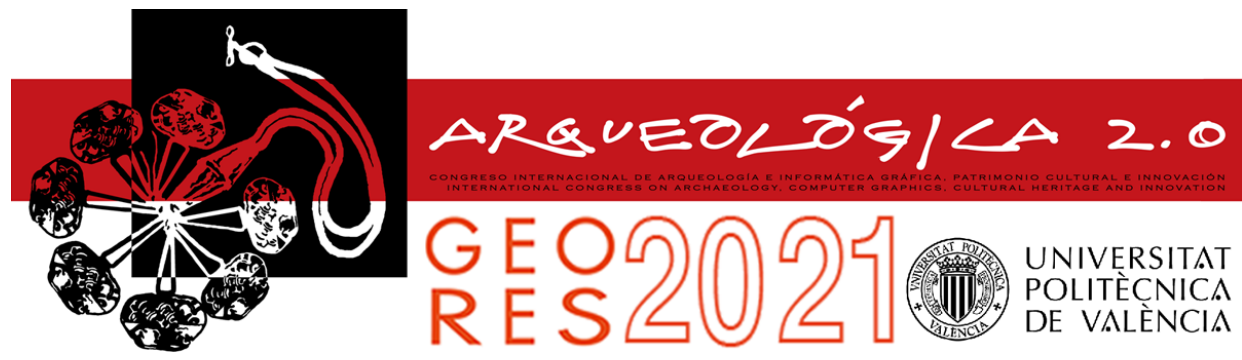

Proceedings of the joint international event $9^{\text {th }}$ ARQUEOLÓGICA

$2.0 \& 3^{\text {rd }}$ GEORES

Valencia (Spain).

26-28 April 2021

\title{
MONITORING LANDSCAPE DEGRADATION IN MEDITERRANEAN AREAS INTEGRATING MEDALUS AND REMOTE SENSING FOR FRAGILE ARCHEOLANDSCAPE PLANNING: THE BASILICATA CASE STUDY
}

\author{
Marzia Gabriele ${ }^{a},{ }^{,}$, Raffaella Brumana ${ }^{a}$, Mattia Previtalia ${ }^{a}$ Alberta Cazzanib \\ a Department of Architecture, Built Environment and Construction Engineering, Politecnico di Milano, Via Ponzio 31, 20133 Milan, Italy. \\ marzia.gabriele@polimi.it; raffaella.brumana@polimi.it; mattia.previtali@polimi.it \\ b Department of Architecture and Urban Studies, Politecnico di Milano, Piazza Leonardo da Vinci 26, 20133 Milan, Italy. \\ alberta.cazzani@polimi.it
}

\begin{abstract}
:
The main objective of the research was identifying the phenomena that generate land degradation (LD), in the Basilicata region's landscape (southern Italy), with a MEDALUS (Kosmas, Ferrara, Briasouli, \& Imeson, 1999) and RS approach, through the help of 6 main indicators (Soil Quality Index, Climate Quality Index, Vegetation Quality Index, Management Quality Index, Landslide Risk Index, Water Availability Index) and through NDVI differencing thresholds evaluation in time intervals, covering a 20 years' time span going from 2000 to 2020 . The Basilicata region saw this phenomenon increased in the past centuries, both because there has never been any monitoring of LD at the regional planning-level, and for the fact that historically the region suffered severe agricultural stress, with enormous deforestations that have led to soil degradation and consequently to the depopulation of the internal marginal areas. These elements caused a strong impact on the potential regional progress, both economic and social, leading to huge ecological damage. The methodology helped to outline the future LD predictions for the region, and consequentially its management possibilities and implications in relation to this critical issue, in order to maintain or restore the pre-existing values, thus integrating the study of Environmentally Sensitive Areas (ESAs) in a scientific validated Decision Support System (DSS), for new coherent and integrated landscape strategies in marginal territories. This objective derives from recognizing the landscape as defined in the European Convention (Council of Europe, 2000) as an important element for community interest, on the cultural, ecological, environmental and social point of view, and as a resource for economic development, pursued by enhancing the preservation of its fundamental component of cultural and natural heritage.
\end{abstract}

Keywords: desertification, soil degradation, remote sensing, archeo-agricultural landscape, landscape preservation, marginal areas

\section{Introduction}

The United Nations Convention to Combat Drought and Desertification (UNCCD) described desertification as the "land degradation (LD) in arid, semi-arid and dry subhumid areas, resulting from various factors, including climatic variations and human activities" (UNCCD 1996) (Fig. 1)

The Mediterranean-type ecosystem is recognized as one of the most imperilled as it is estimated to experience the greatest proportional change in biodiversity by 2100 owing to its sensitivity to land-use change and climate (Sala et al., 2000). The issues and the problems deriving from the study of LD in the Mediterranean ecosystem, must be referred to as the multi-faceted and multidisciplinary aspects of the desertification phenomenon itself. In the field of environmental sciences, having an adequate information base, in terms of consistency and soundness in identifying, defining and evaluating the relevant aggregates (both spatial and temporal), represents a fundamental prerequisite for the application of evaluation models. In addition, for the estimation of environmental vulnerability, this condition is obtained through a reliable and careful collection of the basic data. Knowledge of environmental changes and processes over time and the availability of a large amount of scientific data regarding vegetation, fauna, air, meteorology, hydrology, etc., would permit to distinguish between the forms of degradation caused by anthropic factors and those derived by natural processes (Trotta, Menegoni, Frattarelli, \& lannetta, 2015). Said this, in order to properly evaluate LD, desertification indicators are those which are the most complete for indicating the 
potential risk of desertification. A good indicator should be at a regional level and should be based on available international source materials, including remotely sensed images, topographic map data, climate, soil, and geologic data (Nicholson, Tucker, \& Ba, 1998; Thornes 1995); also, the integration between Geographic Information Systems (GIS) and remote sensing (RS) is the most complete methodology to estimate environmental hazards. On one hand, the GIS-driven reference methodology for the identification of areas vulnerable to desertification in this study is known as ESAs (Environmentally Sensitive Areas), and was developed by Kosmas, Ferrara, Briasouli, \& Imeson, (1999) within the MEDALUS (MEditerranean Desertification And Land USe) project of the European Union, and it provided, on a scale of 1:100000, the application of both biophysical and socio-economic indicators allowing to classify the areas under desertification pressures in critical, fragile and potential. The MEDALUS methodology had numerous applications, assuming the role of standard and uniformly shared methodology, while respecting the local peculiarities of the territory. The ESAs calculation is based on the geometric mean value of four quality indexes Soil Quality Index (SQI), Climate Quality Index (CQI), Vegetation Quality Index (VQI) that are used for the calculation of the environmental conditions and the Management Quality Index (MQI) used for assessing the environmental conditions due to the pressures of anthropogenic activities; in particular, for this case study of Basilicata (Southern Italy), the aim was to search for implementations in the current indexes developed in Gabriele and Previtali (2020) within the framework of the MEDALUS methodology in the aforementioned southItalian region; for this purpose, two new indexes were elaborated to achieve a fine-tuning of the previous study, focusing more on the local peculiarities of the region, namely both landslides and hydrographic network. On the other hand, an additional RS-driven methodology was accomplished in order to monitor the past 20-years evolution of the LD phenomenon at an infra-regional scale, specifically with NDVI differencing applied to change detection. This approach is important in relation to land management goals. Remote sensing is one of the tools of choice for desertification studies, monitoring the phenomenon both at a regional and global scale.

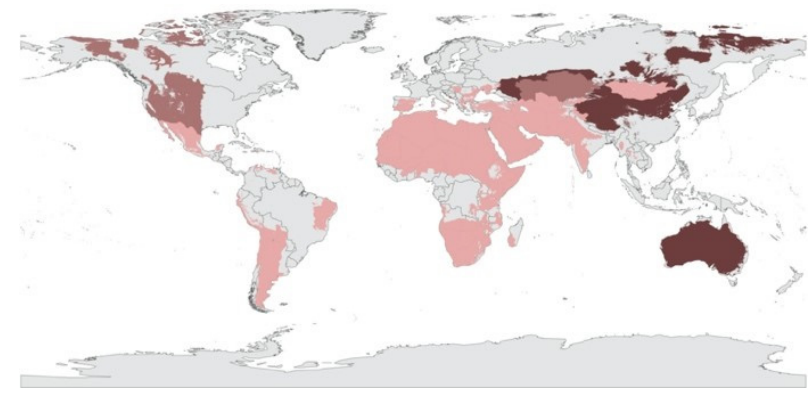

Figure 1: Patterns of aridity 1981-2010 The observed global distribution of the climate classes over the periods from 19511980 and 1981-2010 (Spinoni, Vogt, Naumann, Carrao, \& Barbosa, 2015).

\section{Literature review and related work}

The study of the LD was based on a first literature review aimed at finding a widespread methodology for assessing large scale desertification, that could be easily adapted to include the peculiarities of the places and at the same time have a scientific relevance; it was carried with a specific focus on the Mediterranean area, covering approximately 20 years of research, using widely accepted scientific repositories such as Google Scholar, Scopus, Web-of-Science, et al. For the keyword "sensitivity", "land degradation", "desertification" and "UNCCD", the MEDALUS (MEditerranean Desertification And Land Use) methodology, derived from the framework of MEDALUS projects, financed by the European Commission from 1991 to 1999 , was the most quoted one. This methodology becomes, during the years, one of the most used ones to monitor land sensitivity to degradation and desertification all over the world (Ferrara et al., 2020), based on the evaluation of 4 main Indexes: Climate Quality Index (CQI), Soil Quality Index (SQI), Vegetation Quality Index (VQI) and Management Quality Index (MQI) (Kosmas, Ferrara, Briasouli, \& Imeson, 1999). The review of the adjusted and innovated MEDALUS methodology applied to large scale analysis, with different scientifically valuable cases in Italy (Canora, D'Angella, \& Aiello, 2015; Colantoni, Ferrara, Perini, \& Salvati, 2015; Coluzzi et al., 2019; Ferrara, Mancino, Urbano, Coletta, \& Baffari, 2010; Ladisa, Todorovic, \& Liuzzi, 2012; Trotta, Menegoni, Frattarelli, \& lannetta, 2015; Salvati \& Bajocco, 2011; Salvati et al., 2013), in Asia (Lee et al., 2019), in the rest of Europe (Karamesouti, Panagos, \& Kosmas, 2018; Contador, Schnabel, Gutierrez, \& Fernandez, 2009), in northern Africa (Ait Lamqadem, Pradhan, Saber, \& Rahimi, 2018) and in the Middle east (Bakr, Weindorf, Bahnassy, \& El-Badawi, 2012), confirmed the worldwide efficiency and applicability of the ESA methodology even in the past 10 years, allowing for the harmonization of regional/countrylevel studies and applications, and the more efficient use of global level datasets (Ferrara et al., 2020). Then, a second literature review was carried out in order to find an indicator for evaluating the LD at a mid-regional scale, for a time span of twenty years (2000-2020). The studies found were mainly based on Remote Sensing techniques, showing that with the aggravation of desertification, the surface vegetation, observed through RS, appeared seriously damaged, causing the reduction of the coverage of the biomass, resulting in a lower Vegetation Index (VI) in the remote sensing image (Schlesinger et al., 1990; Zeng, Feng, \& Xiang, 2006; Pan \& Li, 2013; Becerril-Piña, Díaz-Delgado, Mastachi-Loza, \& González-Sosa, 2016). The use of multispectral remote sensing images to extract various indices constructing feature space for extraction and monitoring of ecological environment information currently represents an advanced method for remote sensing monitoring of the ecological environment (Ding, Zhao, Zheng, \& Jiang, 2014). However, up to date, there is no unified mathematical expression that defines all VIs due to the complexity of different light spectra combinations, instrumentation, platforms, and resolutions used. Among the VIs, the change detection through NDVI (Normalized Difference Vegetation Index) resulted in one of the most extensively applied for its sensitivity to the presence, density and condition of vegetation. It is of considerable value as an indicator of environmental change (Eastman, Sangermano, Machado, Rogan, \& Anyamba, 2013), as in fact, temporal analysis of satellitebased NDVI is one of the major remote sensing tools which can identify the depletion of vegetation cover (Kundu, Patel, Saha, \& Dutta, 2017). Change detection is a simple, but effective method for assessing LUCs, carried by comparing vegetation indices from Satellite 
data among different dates (Lyon, Yuan, Lunetta, \& Elvidge, 1998). This method has been documented widely in research, favoured for its accuracy, simplicity in computation, and ease in interpretation (Singh, 1986; Muchoney \& Haack, 1994; Green, Kempka, \& Lackey, 1994; Coppin \& Bauer, 1996; Macleod \& Congalton, 1998; Mancino, Nolè, Ripullone, \& Ferrara, 2014).

\section{A dynamic archaeolandscape: the Basilicata case study}

\subsection{Landscape as the result of the interaction between natural and cultural factors}

The "Built Environment" is progressively intended with an extended meaning, developing from single exceptional monuments to historic centres, urban areas, historical and archaeological sites, architectural objects, natural and cultural landscapes, as well as what we call "cultural heritage" artefacts with human and intangible values. It needs specific care and an integrated approach, in order to analyze and know it and then to process and to manage all the data needed for careful control and deeper understanding of its transformations across the time (past and future) under different challenging issues (human pressures, socio-economic modifications, climate changes, natural hazards) preserving the material authenticity and unicity, as a vehicle for the intangible values.

Referring to this "Built Environment" concept, we consider the landscape as a product of history, which operates on natural environmental pictures through man interventions.

A landscape is a space of various extension for a time of various duration. The lasting works of man, like structures and infrastructures necessary for his life, for his economic, cultural and spiritual actions, overlap the natural substrate and fit into a historical legacy in the process of progressive enrichment.

The complex of natural and cultural features must be analyzed to manage, valorize and rehabilitate outstanding and ordinary landscapes in their dynamic changing.

In this regard, it should be remembered that the European Landscape Convention (ELC, Florence, October 2000), redefines the concept of landscape highlighting the landscape value of the entire territory (including landscapes that might be considered outstanding as well as every day or degraded landscapes), the complex and pervasive meaning of the landscape values, and the necessary reference to perceptions and expectations of the populations (Council of Europe,2000). In this view, focus is not on the islands of excellence, that is on areas of exceptional value, but on the diffuse landscape heritage that represents the common heritage, the identity values (Gambino, 2010).

Landscape is not only construction or structural composition, but it also has an intangible element that reflects the man cultures that created it. Because the landscape is a cultural heritage that is living and dynamic, it is able to assimilate and integrate over time those elements that mark territorial changes, if those modifications are not too violent, too fast or of enormous impact. The problem is not the transformation of the landscape, but the type and means of the transformation. With few exceptions, industry, intensive farming, mass tourism and major contemporary infrastructure in our countries have not transformed the landscape but destroyed it or rendered it uniform. Also, climate and socio-economic changes caused the marginalization of areas that are now fragile and in decay.

Conserving the authenticity of a landscape does not mean maintaining it intact and fossilizing it. Landscape - as already mentioned - is dynamic in itself as it is the result of the constant tension and interaction between nature and man. Thus, it becomes a goal of conserving and valorising those specific and original components, taking into account its dynamic nature.

All this considered, we must also remember that landscape is an archaic complex layered system strongly linked to our archaeological heritage. It is therefore important to support the knowledge of cultural and traditional landscapes or - better - of our archaeolandscapes - considered as a tool to strengthen the identity of communities and to better valorize fragile and deteriorated areas.

\subsection{Basilicata landscape development}

The Basilicata Region has a rich and significant archaeolandscape. Basilicata has been inhabited since ancient times and its agricultural landscape was famous in Magna Graecia with extensive cereal crops on the plateaus, olive groves and vineyards on the hills, as well as vast pastures and woods in the mountain areas.

The landscape of Basilicata presents archaeological elements from the Paleolithic to the Roman age to which are added interesting evidence of the Medieval and Renaissance periods: the result is a complex system of historical sites linked with natural and environmental resources.

Today's Basilicata landscape is a result of the long- term human-environment-climate interactions that have driven the ecological dynamics throughout the Holocene. The agricultural landscape is in some areas still conserved: olive groves, vineyards and chestnut groves produce high quality and renowned products. The historic road system and water network are still readable and characterize the landscape layout. However, historical cartography between the $16^{\text {th }}$ and $18^{\text {th }}$ Centuries documents a much more complex and designed landscape with precious cultivations and vast wooden areas, undoubtedly closer to the ancient one than the current one that is the result of profound transformations of the $20^{\text {th }}$ century.

Basilicata is a region where animal breeding and pastoralism have a long tradition. It is believed that the name Lucania derived from the Latin noun lucus -which means woodland- that characterized the mountain and hilly landscape of the region. Azimonti (1909) in his parliamentary inquiry into the conditions of peasants in the southern provinces, notes that at the beginning of the 1800 s at least half of the region was covered in lush forests. The most emblematic intervention was represented by the consistent and uncontrolled campaign of deforestation and clearing of considerable portions of state property. These deforestation measures were focused on the internal area of the region subjected to a wider context of a systematic recovery operation of spaces that were meant to be converted to cereal crops. 
Moreover, the autarchic policies of the fascist period, known as the "wheat battle", led to a considerable expansion of the areas cultivated with cereals (registering from 1927 to 1930 an increase of 37.000 ha). Milone (1955) referring to the data of Quattrocchi on the wooded area in Italy of 1947, observes that Basilicata had become the poorest region in the wooded heritage (Quattrocchi, 1999). The substantial and massive reduction of the forest heritage had thus further marked the natural instability of the soils, exposing them to landslides and to the erosive activity of torrential rain flows in mountainous and hilly areas. From an economic point of view, the cultivation of these soils, initially registered higher yields than the soils already used for cereal crops, and then realigned it to the regional values.

The geography of soil degradation in today Basilicata sees the region to be one of the most under pressures. The degradation issues concerns (i) the macro- category of climatic factors and the geomorphological characteristics of the soils, responding to particular changes in climatic conditions or to the action of atmospheric agents, with the loss of soil characteristics; (ii) the pressure for the macro-category of the dynamics of social organization, in its most diverse articulations: agricultural, industrial, tourism, building activities. It can be assumed that the Basilicata region well summarizes many basic features of the biogeographic complexity characterizing Mediterranean countries. Both due to the logic and functioning of the agricultural world (abandonment of certain agricultural practices, deterioration of traditional construction heritage, intensification of breeding, depopulation, marginalization of the inner areas), and due to external agents (climate change, aridity, forest fires, etc.).

\section{Materials and methods}

\subsection{The Basilicata case study}

To have the Basilicata region as a paradigmatic case study gave the opportunity to analyse the aforementioned cross-sectoral characteristics that fostered land degradation and that are today vastly assimilated in the entire Lucan territory: (i) the degree of seismicity of the region, and the consequential soil instability and landslides, which have historically redesigned the forms of the settlement for several times; (ii) the soil itself and its intrinsic qualities, specifically, the dominance of clay and sandy soils, which gives the Lucanian territory low degrees of fertility as regards productivity, and a low degree of soil cohesion with strong exposure to the various forms of soil erosion, giving rise to the aforementioned constant landslides, which jeopardize the safety of the settlement and offer considerable difficulties to primary activity, especially in the innermost hilly areas, leading to marginalization; (iii) the methodologies of land management that have taken place in relation to the preservation of natural sites and water elements, both following EU and National laws (e.g.Dir 1992/43/CEE and D.Lgs 42/2004) (iii) the agricultural primary production and livestock density, that contributed to the redefinition of the settlement patterns of the population and to the agricultural activities, reshaping the territorializing processes from a functional and geographic point of view; (iv) vegetation loss patterns (poor biodiversity) that progressively decreased the protective effect on the soil, until the process became irreversible; in this case, unsustainable agronomic practices (deforestation for intensive agricultural purposes) have happened to aggravate the local conditions; (v) climate-topography interactions and trends, characterized by an unequal annual distribution of rainfall with more than $80 \%$ falling from October to March, often in the form of torrential rain leading to the flash-floods and slope erosion patterns, reflecting a negative incidence on the vegetation of the north-exposed slopes; (vi) the water resources and aquifer quality, that filter and regulate freshwater dynamics (both surface and groundwater), although Basilicata has a complex and structured groundwater network, this does not necessarily mean increased water availability, as in fact the region amply suffers from aridity and water scarcity.

The literature review evidenced the MEDALUS methodology as the one suitable to the study scope and application, as it harmonizes multisource databases mainly covering the climate, soil, vegetation and management aspects, whereas some indicators may be excluded and some other may be added into the framework, in order either to adapt the model to the specific environmental conditions, or to improve knowledge about some particular aspects of desertification (Ladisa, Todorovic, \& Liuzzi, 2012).

\subsection{The MEDALUS methodology}

The original MEDALUS method framework is based on four basic indicators specific to the original ESA procedure, i.e., Climate Quality Index (CQI), Soil Quality Index (SQI), Vegetation Quality Index (VQI) and Management Quality Index (MQI) (Kosmas, Ferrara, Briasouli, \& Imeson, 1999). These indicators, obtained by processing certain constituting and representative parameters (variables or sub-indicators) for each individual case capture the main environmental characteristics that are directly or indirectly responsible for land sensitivity to degradation in each territory, and which are determined by climate, soil and vegetation conditions, and by anthropogenic land management specificities. The classes assigned to each sub-indicator must be weighted with certain score values (ranging from 1 , which indicates a low land degradation sensitivity, to 2 , which indicates high sensitivity to degradation), which in the end are processed as a geometric mean for obtaining the main quality indicators. Subsequently, the weighted classes of the main quality indicators are processed using the same averaging procedure, resulting in the Environmentally Sensitive Areas Index (ESAI). In this case study, the weight factors were assigned and based, where possible, on the analysis of the previous literature (Kosmas et al., 2014, Prăvălie, Patriche, \& Bandoc, 2017, Salvati et al., 2013, Vieira et al., 2015; Tavares et al., 2015; Salvati \& Bajocco, 2011). Other parameters, depending on the quality and quantity of the input data and on the characteristics of the study area, were implemented and given a precise score calibrated on the local characteristics. As expressed in the introduction paragraph, one of the final goals of the work was to adjust and implement the previous ESAls presented in Gabriele \& Previtali (2020), which consisted in the evaluation of the three main environmental quality indicators (SQI, CQI, VQI) together with the management quality indicator (MQI), for doing so, there were taken into consideration other characteristics of the Basilicata region as Landslide 
Risk Index (LRI) and Water Availability Index (WAI), assessing in this way a more accurate land desertification sensitivity of the region, calibrated on its peculiarities. LRI defines one of the mainland degradation issues in the region, the landslides, that shaped Basilicata geomorphology, enhanced by the deforestation during centuries. WAl assesses the availability of water resources in a region that is formally characterized by long drought periods and a scarcity of groundwater supplies. By doing so, the MEDALUS method was implicitly implemented with new variables (in addition to the original MEDALUS procedure) reinforcing the basic indicators CQI, SQI, VQI and MQI, and attesting the methodology's adaptability and flexibility according to local and national conditions (Contador, Schnabel, Gutierrez, \& Fernandez, 2009; Bakr, Weindorf, Bahnassy, \& El-Badawi, 2012; Prăvălie, Patriche, \& Bandoc, 2017); the six indicators were then processed using GIS tools (QGIS 3.8 software) in order to obtain the final ESAI.

\subsection{MEDALUS methodology implementations}

The Water Availability Index (WAI) was implemented from the geometric average of four sub-indexes as: water density, groundwater bodies quality, flood risk and aquifer productivity, and calculated as in Eq. (1):

WAI $_{i j}=\left(\right.$ Water Density $_{i j} \times{\text { Groundwater Bodies } \text { Quality }_{i j} \times}$ Flood Risk ${ }_{i j} \times$ Aquifer Productivity $\left._{i j}\right)^{1 / 4}$

The major aquifers of regional importance are in the carbonate hydro structures, characterized by high permeability due to their fracturing and karst. An accurate review of both the National Management Plan of the Hydrographic District of the Southern Apennines and of the transboundary aquifers dataset from UNESCO International Hydrogeological Programme (IGRAC, 2015; Duscher et al., 2015) has shown that the hydrogeological structures and flat areas that fall close to the regional borders, whose aquifers are of national and regional importance, are characterized by high water potential. Therefore, they are a source of conspicuous withdrawals for drinking, irrigation and industrial use. Moreover, flood risk classes were extracted from the National Flood hazard maps and flood risk maps (directive 2007/60 / EC and Italian legislative decree 49/2010), of Distretto dell' Appennino Meridionale (Southern Apennine District) and then scored.

The Landslide Risk Index (LRI) was implemented from the geometric average of two sub-indexes as landslide risk and distance from faults, and calculated as the following Eq. (2):

$L R I_{i j}=\left(\text { Landslide Risk }_{i j} \times \text { Distance from Faults }_{i j}\right)^{1 / 2}$

The knowledge of the spatial distribution of landslide phenomena is crucial to investigate many issues of landscape evolution and its relationships with human activities and land management. Historically, Basilicata has been described as "the most degraded region of southern Italy" as a result of the widespread soil erosion and landslides that it experiences" (Kayser, 1958). The risk deriving from the landslide phenomena, was calculated from the current plan for the defence against hydrogeological risk (PAI Basilicata) and the relationships between the mapped landslide element and the potential elements of risk (loss of life, people injured, damage to properties and disruption of economic activities) falling within its perimeter. For the Distance from Faults subindex, the faults database from International Hydrogeological Map of Europe, (Duscher et al., 2015) was buffered with an interval of $10 \mathrm{mt}$ to $200 \mathrm{mt}$ and then scored.

ESAI Land sensitivity to degradation was defined as the final step in environment quality (soil quality, climate quality, vegetation quality), landslide risk, water availability and management quality assessment based on original methodology (Kosmas, Ferrara, Briasouli, \& Imeson, 1999) classifying the area into four main classes (not affected $(N)$, potentially affected $(P)$, fragile $(F)$ and critical (C)) and 8 sub-classes (N, P, F1, F2, F3; C1, C2, C3). ESAI (Environmentally Sensitive Areas Index), (Fig. 2 ), was obtained from the geometric average of four above mentioned layers using the Eq. (3):

$E S A I_{i j}=\left(S Q I_{i j} \times V Q I_{i j} \times C Q I_{i j} \times M Q I_{i j} \times L R I_{i j} \times W A I_{i j}\right)^{1 / 6}$

The spatial distribution of the ESAI defines $1317.560 \mathrm{~km} 2$ for the non-affected areas ( $\mathrm{N}$ sub-class); $2989.038 \mathrm{~km} 2$ for the potential areas ( $P$ sub-class); $2843.366 \mathrm{~km} 2$ for the first band fragile areas (F1) areas; $2016.629 \mathrm{~km} 2$ for the second band fragile areas (F2); $351.303 \mathrm{~km} 2$ for the third band fragile areas (F3); $24.104 \mathrm{~km} 2$ for the first band critical areas (C1); $1.589 \mathrm{~km} 2$ for the second band critical areas (C2); there are no third band critical areas (C3).

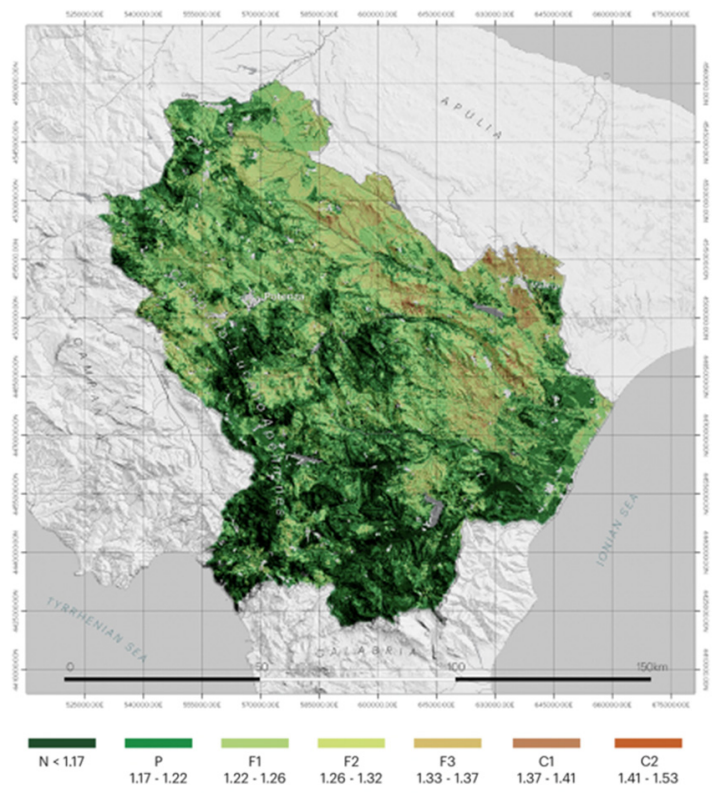

Figure 2: The spatial distribution of the Land Degradation (LD) phenomenon through the ESAI index.

\subsection{NDVI differencing threshold and vegetation change detection}

Image differencing is simply the subtraction of the pixel digital values of an image recorded at one date from the corresponding pixel values of the second date (Hayes \& Sader, 2001), the histogram of the resulting image depicts a range of pixel values from negative to positive numbers, where those clustered around zero represent no change and those at either tail represent reflectance changes from one image date to the next (Jensen, 1996); a threshold value based on the mean $(\mu)$ and standard 
deviation $(\sigma)$ of NDVI differencing image is required in determining real change occurrence Eq. (4):

$\triangle N D V I=\mu \pm n \cdot \sigma$

The threshold identifies three ranges in the normal distribution: (a) the left tail $(\triangle N D V I<\mu-\mathrm{n} \cdot \sigma)$; (b) the right tail $(\triangle N D V I>\mu+\mathrm{n} \cdot \sigma)$; and (c) the central region of the normal distribution $(\mu-\mathrm{n} \cdot \sigma<\Delta N D V I<\mu+\mathrm{n} \cdot \sigma)$. Pixels within the two tails of the distribution are characterized by significant vegetation changes, while pixels in the central region represent no change. The $n$ factor defines the range of dispersion around the mean. This study considered only the negative variation in vegetation cover defined as the area of probable land degradation. The chosen threshold value used for the NDVI image differencing classification was 1.5 and it is expressed with the following Eq. (5):

$$
\triangle N D V I<\mu-1.5 \cdot \sigma
$$

The chosen high-risk area for the study of NDVI differencing assessment is the Fossa Bradanica and a portion of Montagna Materana (Fig. 3). The area falls in the badland area of Basilicata region. Badlands are characterized by their steep, unvegetated slopes, high drainage densities, high rates of erosion and a tendency for the formation of a regolith profile with desiccation cracks in the top 1-5 cm, creating a 'popcorn' surface (Howard, 1994). For the NDVI image differencing, two Landsat TM cloud-free images (path 188, row 32) with 30 x $30 \mathrm{~m}$ spatial resolution were analyzed. The images were acquired during the period between: 13 June - 16 August, for the following years: 2000 and 2019. 12 randomly chosen areas were sampled from the $\Delta$ NDVI 2000-2019, spotting the effective changes in the landscape with a comparison of the National Orthophoto from 2000 and the Basilicata Orthophoto from 2017 (Fig. 4). These two orthophotos were chosen mainly for the fact that they were the closest in terms of time reference to the $\triangle \mathrm{NDVI}$ 2000-2019 and for the availability of data.

\section{Policy addressing}

\subsection{Integration of vulnerability studies in regional DDS}

Availability of trustful, reliable and updated information is of uttermost importance for any decision-making process. The method presented in Section 4 can be considered as a starting point for the construction of a Regional Decision Support System integrating several layers:

- Vulnerability studies to define areas that need specific attention in the planning and in the monitoring stages due to specific fragilities (climatic, orographic, anthropogenic, etc.),

- Risk analysis carried out considering different scenarios (e.g. landslide risk assessment and connected issues, wildfire, etc.)

- Earth Observation-based analysis that can be used for timely and monitoring of ongoing phenomena, identify anomalies with respect to a defined reference scenario and time evolution of specific trends.
The integration of such information into a unique framework can be used twofold. On the one side, it provides to decision-makers an overall view of complex and interlinked phenomena providing a digital twin solution (in this case a Twin Earth) for real-time analysis and simulations. On the other side, the availability of a platform for data communication can be used to raise awareness in citizens and local communities on the issues related to soil degradation and soil sealing. This awareness rising can also determine a more collaborative decision-making process by involving local stakeholders in planning activities by collecting requirements and feedbacks from citizens and local associations.

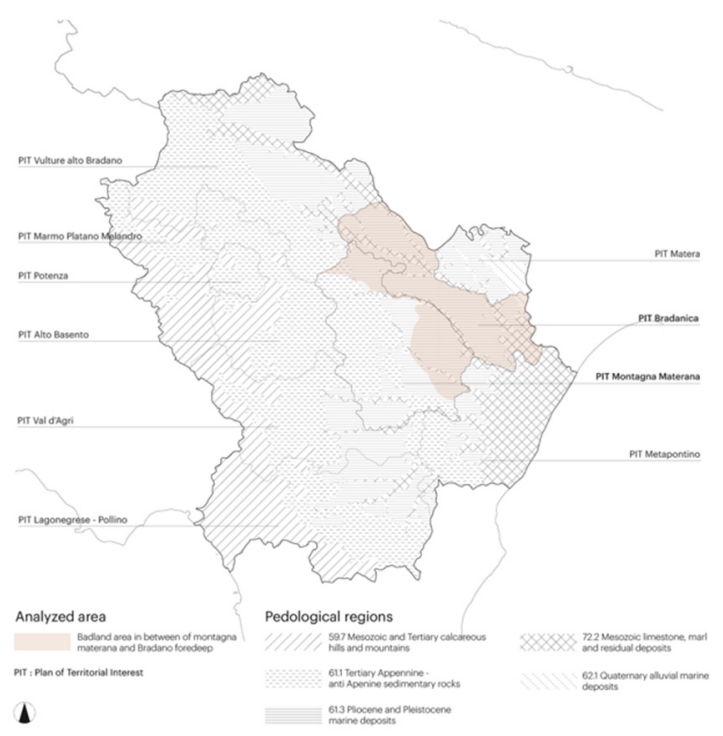

Figure 3: The chosen high-risk area (partially falling into the Montagna Materana and covering the whole Fossa Bradanica), evidenced in pink.

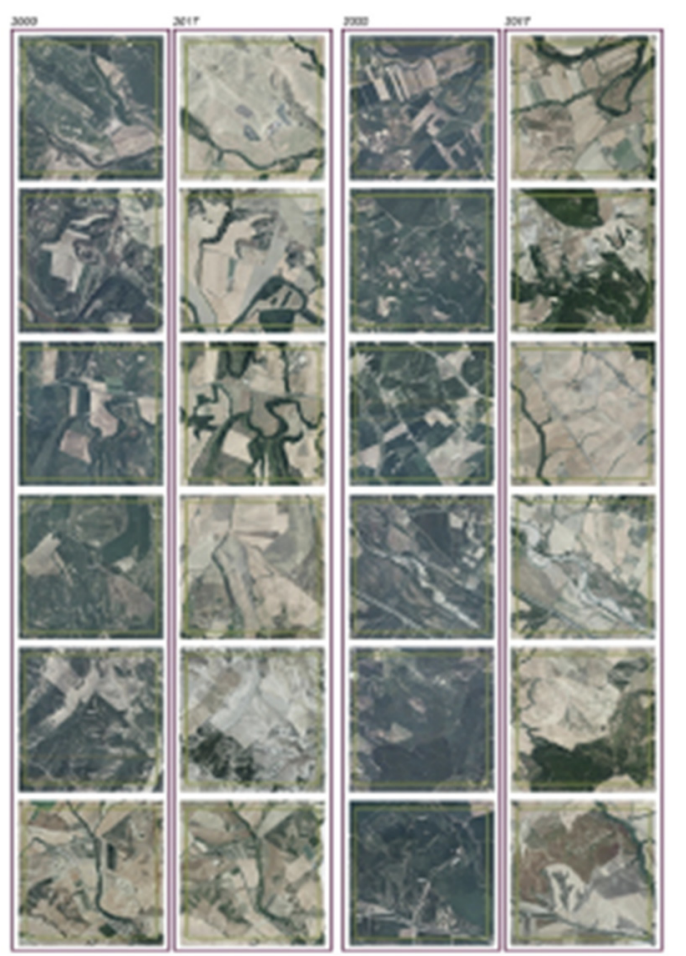

Figure 4: The 12 randomly chosen areas spotting the changes between the National Orthophoto from 2000 and the Basilicata Orthophoto from 2017. 


\subsection{Landscape preservation as an active planning tool}

From the evolution of the landscape concept, it is currently necessary to define methodologies to read and evaluate landscape typologies and features involving natural, historic, perceptive and constructive components, examining decay and transformation problems and understanding social needs and functional options.

The current landscape preservation aims to conserve the historic stratification and to define new compatible plans and uses, identifying the ways to mitigate alteration impacts, to requalificate degraded zones, to re-connect marginalized and fragile areas, to enhance natural, historic and cultural values, to improve documentary and educational options and to manage new projects and opportunities.

In this regard, the already mentioned European Landscape Convention (ELC, Florence, October 2000), underlines landscape policies and practices, listing conservation means and ways to maintain the peculiar features of a landscape, considering the natural and cultural value. It also details the possible actions to guarantee landscape management, considering and harmonizing the transformation caused by social, economic and environmental changes (Council of Europe, 2000).

Management must be dynamic and move towards improving landscape quality in accordance with local goals and with efforts to valorize, conserve or create landscapes. That landscape planning covers the surveying, analyzing, the understanding process in order to preserve the historic values and to design new compatible landscapes.

Therefore, the ELC is an innovative document that foregrounds how landscape preservation cannot be limited to exceptional sites, cannot be dealt with by a minority and cannot be imposed by law, but requires a broad strategy that encompasses the entire territory and the connected communities and activities.

It is important to highlight that the meaning of conservation is gradually changed during the last decades, both in the nature conservation field and in the cultural heritage conservation field. In both fields, it becomes clear that effective conservation of the values to be protected cannot be ensured by mere measures of limitation or prohibition (even if such measures are often absolutely essential). It requires active intervention. There cannot be authentic conservation without new values production, and indeed the conservation is, for the contemporary society, "the innovation privileged place".

In this perspective, landscape planning can play a particularly important role. A new landscape active preservation must target both the social enhancement of extraordinary landscapes (often already recognized and protected by national laws) and ordinary ones (almost always lacking such recognition). It is necessary to set cooperation between government bodies and communities so that active criteria can be drafted to manage the landscape as a place in which people live and as an asset to be transmit to future generations in a richer - and not impoverished- state (Gambino, 2010).
As noted, the landscape needs to be viewed as a dynamic organism and, in historical terms, it must be understood as the result of a series of temporal sequences created by the complex interrelations over time between man and nature. In this regard it is important to rise the knowledge integrating natural and anthropic elements of the interpretative analysis in order to define planning tools, considering the ecosystem approach to plan the landscape as a system of ecosystems (Ferrari \& Pezzi, 2013).

Consequently, landscape valorization strategies need to consider the multiple transformations that have taken place and analyze the effects on the landscape of the human and nature actions in order to define planning tools and management criteria capable of conserving and/or rehabilitating landscape meanings and values.

In order to make it possible, it is necessary to increase the integration between territorial and landscape planning tools and promote shared planning and landscape design at a Regional scale.

\section{Conclusions}

Land degradation is a major issue in many areas of the world. For this reason, the availability of methodologies to define the levels of vulnerability within a specific area should take into consideration two diverging requirements: i) the definition of a standardized approach to be used in various areas and ii) the specific characteristics and factors influencing the land degradation phenomenon that may vary from site to site. The presented approach tries to use a well-established and standardized framework (i.e., the MEDALUS methodology) customizing to take into the specific vulnerability aspects of the Basilicata region by adding two new indexes (WAI and LRI) to the original formulation. Starting from the identified vulnerable areas Earth Observation data were used to have the first map of areas under stress at the regional level. The derived results from this analysis can be considered as a starting point for further in-depth analysis. Indeed, the secretion of a unique threshold for the entire region is not taking into consideration localized phenomena connected to difference in vegetation activity and phenology as well as the difference in the land cover. The definition of a more robust multi-threshold analysis will be investigated in further works.

However, the integration of both evaluations contributed to achieving the final goal of the research, which mainly consisted in identifying the phenomena that generate degradation in the landscape, therefore outlining the future management possibilities and implications in relation to this critical issue, in order to maintain or restore the pre-existing values, or to support the creation of new coherent and integrated landscape strategies. This objective derives from recognizing the landscape as defined in the already mentioned European Landscape Convention Landscape. In fact, performs important functions of community interest, on the cultural, ecological, environmental and social point of view, and is also a resource for economic development, without forgetting that it is a fundamental component of archaeological, cultural and natural heritage too.

The final assumption is that each territory is constantly changing, so the landscape transformations are 
inevitable: the problem is to evaluate how these transformations contribute to modify the landscape. In fact, these must be consciously guided and managed by appropriate planning policies. In the case of degradation, the transformation of the landscape is the result of the evolution of centuries and of a series of extremely complex phenomena that it is impossible to consider reversible. This means that we can treat, in this situation, the landscape as a compromised landscape, that defines definitive loss of the characters, quality and values of a landscape, that determines the disappearance of its integrity from a perceptual and functional point of view and relationships and loss of the references through which the population attributes collective value and quality to the landscape. Degradation and alteration can deeply compromise the landscape, deleting the preexisting components and values: in this situation it is possible to add new functions and features in order to create new coherent and integrated landscape values, using correct planning and management policies. The European Landscape Convention reaffirms how, in the era of globalization, the problems relating to the protection and development of rural and often fragile areas are extremely relevant: protecting and enhancing the agricultural landscape and promoting eco-sustainable agriculture are not only necessities for economic and social development of those areas, but also for cultural and environmental ones.

\section{References}

Ait Lamqadem, A., Pradhan, B., Saber, H., \& Rahimi, A. (2018). Desertification sensitivity analysis using MEDALUS model and GIS: a case study of the Oases of Middle Draa Valley, Morocco. Sensors, 18(7), 2230. https://doi.org/10.3390/s18072230

Azimonti, E. (1909). IP, Basilicata. Relazione del delegato tecnico, Basilicata e Calabrie, tomo I, vol. V, $236-23$.

Bakr, N., Weindorf, D. C., Bahnassy, M. H., \& El-Badawi, M. M. (2012). Multi-temporal assessment of land sensitivity to desertification in a fragile agro-ecosystem: Environmental indicators. Ecological indicators, 15(1), $271-280$. https://doi.org/10.1016/j.ecolind.2011.09.034

Becerril-Piña, R., Díaz-Delgado, C., Mastachi-Loza, C. A., \& González-Sosa, E. (2016). Integration of remote sensing techniques for monitoring desertification in Mexico. Human and Ecological Risk Assessment: An International Journal, 22(6), 1323-1340. https://doi.org/10.1080/10807039.2016.1169914

Canora, F., D'Angella, A., \& Aiello, A. (2015). Quantitative assessment of the sensitivity to desertification in the Bradano River basin (Basilicata, southern Italy). Journal of Maps, 11(5), $745-759$. https://doi.org/10.1080/17445647.2014.980857

Colantoni, A., Ferrara, C., Perini, L., \& Salvati, L. (2015). Assessing trends in climate aridity and vulnerability to soil degradation in Italy. Ecological indicators, 48, 599-604. https://doi.org/10.1016/j.ecolind.2014.09.031

Coluzzi, R., D’Emilio, M., Imbrenda, V., Giorgio, G. A., Lanfredi, M., Macchiato, M., \& Telesca, V. (2019). Investigating climate variability and long-term vegetation activity across heterogeneous Basilicata agroecosystems. Geomatics, Natural Hazards and Risk, 10(1), 168-180. https://doi.org/10.1080/19475705.2018.1513872

Contador, J. L., Schnabel, S., Gutierrez, A. G., \& Fernandez, M. P. (2009). Mapping sensitivity to land degradation in Extremadura. SW Spain. Land Degradation \& Development, 20(2), 129-144. https://doi.org/10.1002/ldr.884

Council of Europe (2000). European landscape convention. US/ICOMOS Scientific Journal, 2, 88-92.

Coppin, P. R., \& Bauer, M. E. (1996). Digital change detection in forest ecosystems with remote sensing imagery. Remote sensing reviews, 13(3-4), 207-234. https://doi.org/10.1080/02757259609532305

Ding, Y., Zhao, K., Zheng, X., \& Jiang, T. (2014). Temporal dynamics of spatial heterogeneity over cropland quantified by time-series NDVI, near infrared and red reflectance of Landsat $8 \mathrm{OLI}$ imagery. International Journal of Applied Earth Observation and Geoinformation, 30, 139-145. https://doi.org/10.1016/j.jag.2014.01.009

Duscher, K., Günther, A., Richts, A., Clos, P., Philipp, U., \& Struckmeier, W. (2015). The GIS layers of the "International Hydrogeological Map of Europe 1: 1,500,000" in a vector format. Hydrogeology journal, 23(8), 1867-1875. https://doi.org/10.1007/s10040-015-1296-4

Eastman, J. R., Sangermano, F., Machado, E. A., Rogan, J., \& Anyamba, A. (2013). Global trends in seasonality of normalized difference vegetation index (NDVI), 1982-2011. Remote Sensing, 5(10), 4799-4818. https://doi.org/10.3390/rs5104799

Ferrara, A., Mancino, G., Urbano, V., Coletta, V., \& Baffari, P. (2010). Analisi delle potenzialità applicative del metodo ESA (Environmental Sensitive Areas) e aggiornamento della carta delle aree sensibili alla desertificazione della Basilicata. Forest@-Journal of Silviculture and Forest Ecology, 7(4), 133. https://doi.org/10.3832/efor0627-007

Ferrara, A., Kosmas, C., Salvati, L., Padula, A., Mancino, G., \& Nolè, A. (2020). Updating the MEDALUS-ESA Framework for Worldwide Land Degradation and Desertification Assessment. Land Degradation \& Development. https://doi.org/10.1002/ldr.3559

Ferrari, C., \& Pezzi, G. (2013). L'ecologia del paesaggio. Bologna, II Mulino.

Gabriele, M., \& Previtali, M. (2020). A GIS and Remote Sensing Approach for Desertification Sensitivity Assessment in 
Basilicata Region (Italy). In Proceedings of the 2020 3rd International Conference on Geoinformatics and Data Analysis (pp. 62-66).

Gambino, R. (2010). Parchi e paesaggi d'Europa. Un programma di ricerca territoriale. Ri-Vista, 14.

Green, K., Kempka, D., \& Lackey, L. (1994). Using remote sensing to detect and monitor land-cover and land-use change. Photogrammetric engineering and remote sensing, 60(3), 331-337.

Hayes, D. J., \& Sader, S. A. (2001). Comparison of change-detection techniques for monitoring tropical forest clearing and vegetation regrowth in a time series. Photogrammetric engineering and remote sensing, 67(9), 1067-1075.

Howard, A. D. (1994). Badlands. In Geomorphology of desert environments (pp. 213-242). Springer, Dordrecht. https://doi.org/10.1007/978-94-015-8254-4_9

IGRAC (International Groundwater Resources Assessment Centre), UNESCO-IHP (UNESCO International Hydrological Programme). (2015). Transboundary Aquifers of the World [map]. Edition 2015. Scale 1: 50000000. Delft, Netherlands: IGRAC, 2015.

Jensen, J. R. (1996). Introductory digital image processing: a remote sensing perspective (No. Ed. 2). Prentice-Hall Inc.

Karamesouti, M., Panagos, P., \& Kosmas, C. (2018). Model-based spatio-temporal analysis of land desertification risk in Greece. Catena, 167, 266-275. https://doi.org/10.1016/j.catena.2018.04.042

Kayser, B. (1958). Recherches sur les sols et l'érosion en Italie méridionale, Lucanie (Doctoral dissertation, Paris).

Kosmas, C., Ferrara, A., Briasouli, H., \& Imeson, A. (1999). Methodology for mapping environmentally sensitive areas (ESAs) to desertification. The medalus project Mediterranean desertification and land use. Manual on key indicators of desertification and mapping Environmentally Sensitive Areas to desertification, 31-47.

Kosmas, C., Kairis, O., Karavitis, C., Ritsema, C., Salvati, L., Acikalin, S., \& Belgacem, A. (2014). Evaluation and selection of indicators for land degradation and desertification monitoring: methodological approach. Environmental management, 54(5), 951-970.

Kundu, A., Patel, N. R., Saha, S. K., \& Dutta, D. (2017). Desertification in western Rajasthan (India): an assessment using remote sensing derived rain-use efficiency and residual trend methods. Natural Hazards, 86(1), 297-313.

Ladisa, G., Todorovic, M., \& Liuzzi, G. T. (2012). A GIS-based approach for desertification risk assessment in Apulia region, SE Italy. Physics and Chemistry of the Earth, Parts a/B/C, 49, 103-113. https://doi.org/10.1016/j.pce.2011.05.007

Lee, E. J., Piao, D., Song, C., Kim, J., Lim, C. H., Kim, E., \& Lee, W. K. (2019). Assessing environmentally sensitive land to desertification using MEDALUS method in Mongolia. Forest Science and Technology, 15(4), $210-220$. https://doi.org/10.1080/21580103.2019.1667880

Lyon, J. G., Yuan, D., Lunetta, R. S., \& Elvidge, C. D. (1998). A change detection experiment using vegetation indices. Photogrammetric engineering and remote sensing, 64(2), 143-150.

Macleod, R. D., \& Congalton, R. G. (1998). A quantitative comparison of change-detection algorithms for monitoring eelgrass from remotely sensed data. Photogrammetric engineering and remote sensing, 64(3), 207-216.

Mancino, G., Nolè, A., Ripullone, F., \& Ferrara, A. (2014). Landsat TM imagery and NDVI differencing to detect vegetation change: assessing natural forest expansion in Basilicata, southern Italy. Iforest-Biogeosciences and Forestry, 7(2), 75. https://doi.org/10.3832/ifor0909-007

Milone, F. (1955). L'Italia nell'economia delle sue regioni. Edizioni Scientifiche Einaudi, Torino.

Muchoney, D. M., \& Haack, B. N. (1994). Change detection for monitoring forest defoliation. Photogrammetric engineering and remote sensing, 60(10), 1243-1252.

Nicholson, S. E., Tucker, C. J., \& Ba, M. B. (1998). Desertification, drought, and surface vegetation: An example from the West African Sahel. Bulletin of the American Meteorological Society, 79(5), 815-830. https://doi.org/10.1175/15200477(1998)079<0815:DDASVA>2.0.CO;2

Pan, J., \& Li, T. (2013). Extracting desertification from Landsat TM imagery based on spectral mixture analysis and AlbedoVegetation feature space. Natural hazards, 68(2), 915-927.

Prăvălie, R., Patriche, C., \& Bandoc, G. (2017). Quantification of land degradation sensitivity areas in Southern and Central Southeastern Europe. New results based on improving DISMED methodology with new climate data. Catena, 158, 309-320. https://doi.org/10.1016/j.catena.2017.07.006

Quattrocchi, U. (1999). CRC World Dictionary of Plant Names: Common Names, Scientific Names, Eponyms. Synonyms, and Etymology (Vol. 4). CRC press.

Sala, O. E., Chapin, F. S., Armesto, J. J., Berlow, E., Bloomfield, J., Dirzo, R., \& Leemans, R. (2000). Global biodiversity scenarios for the year 2100. Science, 287(5459), 1770-1774. https://doi.org/10.1126/science.287.5459.1770

Salvati, L., \& Bajocco, S. (2011). Land sensitivity to desertification across Italy: past, present, and future. Applied Geography, 31(1), 223-231. https://doi.org/10.1016/j.apgeog.2010.04.006 
Salvati, L., Mancino, G., De Zuliani, E., Sateriano, A., Zitti, M., \& Ferrara, A. (2013). An expert system to evaluate environmental sensitivity: a local-scale approach to desertification risk. Applied ecology and environmental research, 11(4), 611-627.

Schlesinger, W. H., Reynolds, J. F., Cunningham, G. L., Huenneke, L. F., Jarrell, W. M., Virginia, R. A., \& Whitford, W. G. (1990). Biological feedbacks in global desertification. Science, 247(4946), 1043-1048. https://doi.org/10.1126/science.247.4946.1043

Singh, A. (1986). Change detection in the tropical forest environment of northeastern India using Landsat. Remote sensing and tropical land management, 44, 273-254.

Spinoni, J., Vogt, J., Naumann, G., Carrao, H., \& Barbosa, P. (2015). Towards identifying areas at climatological risk of desertification using the Köppen-Geiger classification and FAO aridity index. International Journal of Climatology, 35(9), 2210-2222. https://doi.org/10.1002/joc.4124

Tavares, J. D. P., Baptista, I., Ferreira, A. J., Amiotte-Suchet, P., Coelho, C., Gomes, S., \& Bentub, J. (2015). Assessment and mapping the sensitive areas to desertification in an insular Sahelian mountain region Case study of the Ribeira Seca Watershed, Santiago Island, Cabo Verde. Catena, 128, 214-223. https://doi.org/10.1016/j.catena.2014.10.005

Thornes, J. B. (1995). Mediterranean desertification and the vegetation cover. Mediterranean desertification and the vegetation cover., 169-194.

Trotta, C., Menegoni, P., Frattarelli, F. M. M., \& lannetta, M. (2015). Assessing desertification vulnerability on a local scale: the Castelporziano study case (central Italy). Rendiconti Lincei, 26(3), 421-450. https://doi.org/10.1007/s12210-0140362-5

United Nations Convention to Combat Desertification (Secretariat). (1999). United Nations Convention to Combat Desertification in Those Countries Experiencing Serious Drought And/or Desertification, Particulary in Africa. Secretariat of the United Nations Convention to Combat Desertification.

Vieira, R. D. S. P., Tomasella, J., Alvalá, R. C. S., Sestini, M. F., Affonso, A. G., Rodriguez, D. A., \& De Oliveira, S. B. P. (2015). Identifying areas susceptible to desertification in the Brazilian northeast. Solid Earth, 6(1), $347-360$. https://doi.org/10.5194/se-6-347-2015

Zeng, Y., Feng, Z., \& Xiang, N. (2006). Albedo-NDVI space and remote sensing synthesis index models for desertification monitoring. Scientia Geographica Sinica, 26(1), 75. 